\title{
Detection of mRNA for Alpha-3 Chain of Type IV Collagen in the Glomerular Epithelium, and the Effect of Perfused Elastase on Its Expression
}

\author{
Shoji Nogae ${ }^{1, a}$ Mari Michimata1,b Tsutomu Arakib Michiko Suzukib \\ Itsuro Kazamab Sadayoshi Ito ${ }^{a}$ Yutaka Imai ${ }^{b}$ Mitsunobu Matsubarab \\ aDepartment of Nephrology, Endocrinology and Vascular Medicine, Tohoku University School of Medicine, and \\ bDepartment of Clinical Pharmacology and Therapeutics, Tohoku University Graduate School of Medicine and \\ Pharmaceutical Science, Sendai, J apan
}

\section{Key Words}

Glomerular basement membrane - Proteinuria .

Polymorphonuclear leukocytes

\begin{abstract}
Background: The type IV collagen is a complex of trimetric molecule composed of six genetically distinct polypeptide chains; $\alpha 1-6(I V)$. Since $\alpha 3$ (IV) distribute specifically in the glomerular basement membrane (GBM) of glomerular capillary, we tried to develop the detection methods for the transcripts of $\alpha 3$ (IV) in glomerular epithelial cells (GEC) which produce most of the components for GBM. Then, using these molecular techniques, the influence of elastase, one of the proteases released from activated polymorphonuclear leukocytes at the site of inflammation, on GEC was determined as manifested by expressional alteration of $\alpha 3(\mathrm{IV})$ mRNA. Methods: DIG-labeled oligo-DNA probe designating non-collagenous region of $\alpha 3$ (IV) was used for in situ hybridization.
\end{abstract}

These authors contributed equally to this article.
Semiquantitative measurement of $\alpha 3$ (IV) in the renal cortex was performed by PCR reactions, each reaction being normalized by that for GAPDH. Then, the femoral artery of each of 18 Sprague-Dawley rats was catheterized and the left kidney was perfused with saline alone $(0.5 \mathrm{ml})$ or saline containing $100 \mu \mathrm{g} / \mathrm{ml}$ elastase. After collection of urine for $24 \mathrm{~h}$, the left kidney was harvested for analysis of mRNA ( 4 for in situ hybridization and 5 kidneys for PCR analysis). Results: Antisense cDNA probe and PCR reaction well identified $\alpha 3$ (IV) mRNA in the cytoplasm of GEC and in the renal cortex, respectively. Urinary protein excreted by rats with elastase perfusion was $47.2 \pm$ $3.8 \mathrm{mg} / 24 \mathrm{~h}$ but this was only $13.9 \pm 1.1 \mathrm{mg} / 24 \mathrm{~h}$ in control rats (mean \pm SEM, $p<0.05$ ). In situ hybridization demonstrated that expression of $\alpha 3$ (IV) mRNA in GEC was focally or diffusely reduced in the glomeruli of rats with elastase perfusion, whereas the transcripts were well stained in GEC of controls. PCR analysis showed about $25 \%$ decrease in transcripts of $\alpha 3(\mathrm{IV})$ in the renal cortex of rats with elastase perfusion compared to those of control rats. Conclusions: $\alpha 3(\mathrm{IV})$ mRNA was identified specifically in the GEC in the glomeruli. Co-incidence of proteinuria and reduced $\alpha 3$ (IV) expression by elastase suggests adverse effects of elastase on GEC and close association between proteinuria and GEC injury.

Copyright $\odot 2002$ S. Karger AG, Base

Mitsunobu Matsubara, MD, $\mathrm{PhD}$

Department of Clinical Pharmacology and Therapeutics

Tohoku University Graduate School of Medicine and Pharmaceutical Science

1-1 Seiryo-cho, Aoba-ku, Sendai 980-8574 (Japan)

Tel. +81 22717 7775, Fax +81 22717 7776, E-Mail mmitsu2i@mail.cc.tohoku.ac.jp
Fax +4161306 1234 E-Mail karger@karger.ch www.karger.com

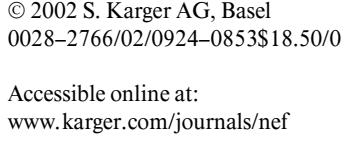




\section{Introduction}

Type IV collagen is the main component of the basement membrane, which is ubiquitous sheet-like extracellular structure separating organ cells from interstitial connective tissue. The basement of renal glomeruli (GBM) is a unique type of basement membrane forming a single, well-defined layer located between endothelial cells and the epithelial podocytes. The GBM has been the focus of intensive research because it is believed to function as the actual renal filtration barrier for macromolecules. Most of the components for GBM including type IV collagen, however, are produced by glomerular epithelial cells (GEC) [1-3]. Therefore, GEC play an important role to maintain the normal structure of GBM, and thus, their condition may be critical especially when GBM was degradated and required to be repaired.

The type IV collagen network forms the structural skeleton of basement membrane [4]. It is a complex of trimetric molecule composed of at least six genetically distinct polypeptide chains; $\alpha 1$ (IV), $\alpha 2(\mathrm{IV}), \alpha 3(\mathrm{IV}), \alpha 4(\mathrm{IV})$, $\alpha 5(I V)$, and $\alpha 6$ (IV) [5-7]. These assemble into different isoforms of triple-helical molecules, the most abundant combination being $[\alpha 1(\mathrm{IV})]_{2} \alpha 2$ (IV). Although little is known about the composition of molecules containing the minor chain $\alpha 3(\mathrm{IV}), \alpha 4(\mathrm{IV}), \alpha 5(\mathrm{IV})$, and $\alpha 6(\mathrm{IV})$, recent studies using specific antibodies demonstrated that $\alpha 3(\mathrm{IV})$ and $\alpha 4$ (IV) distributed only in GBM of glomerular capillary and in limited part of basement membrane of the proximal tubules $[7,8]$, whereas $\alpha 1(\mathrm{IV})$ and $\alpha 2(\mathrm{IV})$ did also in the mesangial matrix, Bowman's capsule, and tubular basement membrane. These findings indicate that $\alpha 3$ (IV) and $\alpha 4$ (IV) is considered to be produced specifically by GEC in the glomeruli, and the transcripts of these components may be located only in glomerular epithelium in a glomerulus. Therefore, in the present study, we try to detect the mRNA expression for $\alpha 3$ (IV) using in situ hybridization and, then, to semiquantify its transcripts in renal cortex by PCR technique.

It has long been recognized in animal experiments that the proteases released from polymorphonuclear leukocytes $(\mathrm{PMN})$ adherent to the glomerular capillary wall may induce glomerular injury $[9,10]$. Recently, Johnson et al. $[11,12]$ directly demonstrated that renal perfusion of active elastase, one of active serine proteases released from PMN, results in severe proteinuria. Furthermore, Heeringa et al. [13] showed that such renal perfusion of active elastase degraded GBM, leading to the loss of polyanionic structure of GBM and induction of proteinuria. In addition to degradation of extracellular matrix proteins, other studies have shown that neutral serine proteases can also injure endothelial cells (EC) [14, 15], suggesting the adverse effect of circulating elastase on glomerular EC. However, little is known about the effects of elastase on GEC, even though GEC is thought to reproduce GBM components to repair the GBM when injured by elastase. Therefore, the condition of GEC after glomerular injury by elastase is to be elucidated for the evaluation of progression of glomerular lesions. We assess the condition of GEC, using the detection methods for $\alpha 3$ (IV) mRNA developed in the present study, according to the hypothesis that mRNA expression for $\alpha 3$ (IV) may remain unchanged or enhanced to repair degraded GBM when the GEC are kept in good condition even after renal perfusion of elastase, whereas, it will be reduced when the GEC themselves are damaged by circulating elastase. The results suggest the adverse effect of elastase on GEC, which may influence on the progression of glomerular lesion.

\section{Materials and Methods}

\section{Detection of mRNA for $\alpha 3(I V)$}

In situ Hybridization. The antisense oligo-DNAs were designed to frame a part of non collagenous domain ( $\mathrm{NC1}$ domain) of $\alpha 3$ chain as follows:

Antisense:

gtggtgaatcgctgtaagcagctgcccagagtaccaaggtcttgtccatgggegtgctca. Sense:

tgagcacgcccatggacaagaccttggtactctgggcagctgcttacagcgattcaccac.

Labeling and staining was performed as previously reported [16, 17]. Briefly, these oligo-DNAs were labeled at their 3 '-end with DIG11-dUTP. PFA-fixed specimens were cut into $6 \mu \mathrm{m}$ thick sections and hybridized with $100 \mathrm{ng} / \mathrm{ml}$ DIG-labeled probes. Anti-digoxigenin antiserum conjugated with ALPL (Boehringer Mannheim, Mannheim, Germany) was used to detect the distribution of DIG, and site of ALP was visualized by reaction with NBT/BCIP.

PCR for $\alpha 3(I V)$ Transcripts. Semiquantitative PCR was designed by modifying our previous technique of competitive PCR [18]. A pair of PCR primers was designed to frame the part of $\alpha 3$ chain, which is located in the NC domain of the chain. Examination of the nucleotide sequence by the dye-termination method using a genetic analyzer (ABI PRISM ${ }^{\mathrm{TM}}$ 310, Perkin Elmer, Conn., USA), showed $100 \%$ identical to that of the partial fragment of $\alpha 3$ chain. After confirming the sequential increase in signal densities according to increment in PCR cycles, series of PCRs using different amount of sample cDNA were performed using primer sets for GAPDH as control (25 cycles) or for $\alpha 3$ (IV) (35 cycles) to confirm the sensitivity of PCR analysis. The intensity of the bands in an agarose gel was measured using a densitometer. Finally, all five samples from each condition (saline perfusion and elastase perfusion) were analyzed and $\alpha 3$ chain density signal was normalized to that of GAPDH.

Animal Experiments for Renal Elastase Perfusion

Eighteen male Sprague-Dawley rats weighing 250-300 g (10 weeks of age) were used in the present study. The rat was anesthe- 
Fig. 1. Localization of transcripts for $\alpha 3(\mathrm{IV})$. A Glomerular section from a representative control saline perfused rat, which was hybridized with the Dig-antisense probe. Note the strong positive signal in the cytoplasm of glomerular epithelial cells (arrow). B Glomerular section hybridized with the sense probe. No definite signals were observed in glomerular epithelial cells (arrow). $\times 200$.
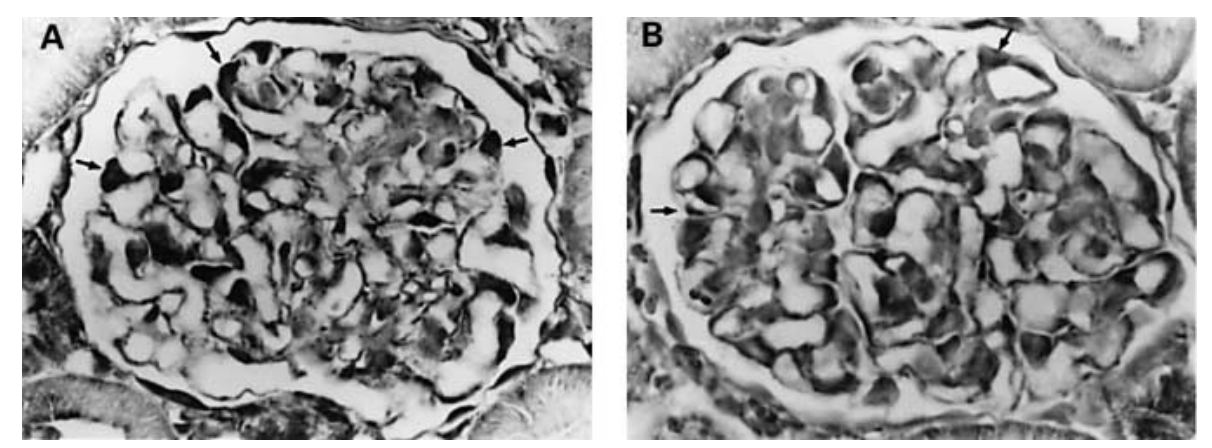

tized by ether, and a polyethylene PE-50 catheter was introduced $4 \mathrm{~cm}$ into the femoral artery with its tip close to the left renal artery. The aorta and inferior vena cava were exposed and a clamp was applied to the aorta above the left renal artery and another clamp to the left renal vein. A puncture in the left renal vein allowed blood and perfusion fluid to escape which were collected by cotton wool balls placed in that area. Initially, saline was perfused until no visible blood escaped from the punctured renal vein. Then, rats were perfused with either saline alone (control rats) or saline containing $100 \mu \mathrm{g} / \mathrm{ml}$ elastase $(0.5 \mathrm{ml})$. Elastase purified from human neutrophils was purchased from Wako Pure Chemical Industries (Osaka, Japan). After $3 \mathrm{~min}$, the kidneys were cleared with saline and blood flow was restored. Total ischemia time was always $<8 \mathrm{~min}$. After surgery, rats were treated as reported previously $[16,19]$. Briefly, the catheter placed in the aorta was filled with heparinized $(100 \mathrm{U} / \mathrm{ml})$ $0.9 \% \mathrm{NaCl}$ and exteriorized and secured at the nape of the neck as previously reported, and were allowed to recover from anesthesia for $2 \mathrm{~h}$ under a heat lamp. Rats were then placed in individual metabolic cages for $24 \mathrm{~h}$ with free access to water containing 5\% dextrose, in addition to food, to ensure adequate postoperative hydration. Urine was collected continuously. The following day, after urine collection, blood was sampled $(3 \mathrm{ml})$ through the catheter, then rats were deeply anesthetized with ether. Left kidneys from 10 rats $(5$ controls and 5 test rats) were then perfused with saline through the catheter, harvested, divided into two parts, cortex and medulla, and homogenized in $4 M$ guanide for total RNA extraction. Left kidneys of the remaining 8 rats ( 4 controls and 4 rats with elastase perfusion) were perfused with $4 \%$ paraformaldehyde through the aortic catheter for in situ hybridization. The experimental protocol was approved by the Ethics Review Committee for Animal Experimentation of Tohoku University School of Medicine.

Creatinine (Cr), urea (BUN), and albumin (ALB) concentrations in plasma and plasma electrolytes were measured by an autoanalyzer (SYNCHRON CX-7, Beckman Coulter K.K., Calif., USA). Urinary albumin level was measured spectrophotometrically by binding with Coomassie brilliant blue G-250 (Tonein-TP II, Otsuka Pharmaceuticals, Tokyo, Japan). Differences between physiological and laboratory data were examined for statistical significance using unpaired $t$ test. Data are expressed as mean \pm SEM. $p<0.05$ was considered significant.

\section{Results}

\section{Detection of $m R N A$ for $\alpha 3(I V)$}

In situ Hybridization. Figure 1 shows the localization of transcripts for $\alpha 3$ (IV). When glomerular sections from control rats perfused with saline were hybridized with the DIG-antisense probe, a strong positive signal was clearly detected in the cytoplasm of glomerular epithelial cells, but not in those of mesangial cells or endothelial cells (fig. 1A). In contrast, no definite staining was found even in GEC with the sense probe (fig. 1B), which was used as a negative control in every experiment.

PCR Analysis. Figure 2a demonstrates a series of different amounts of RNA with 25 cycles of PCR reaction, showing the linear increase in the GAPDH signal density between 25 and 75 ng RNA. Then, for the analysis of GAPDH transcripts signals we used 50 ng RNA and 25 cycles of PCR reaction. Figure $2 b$ depicts a series of different amount of RNA ( 35 cycles) for the analysis of transcripts for $\alpha 3(\mathrm{IV})$, showing again a linear increase in signal density between 12.5 and $37.5 \mathrm{ng}$ RNA. Thus, we compared the transcript signals for $\alpha 3$ (IV) using $25 \mathrm{ng}$ RNA with 35 cycles.

\section{Effect of Elastase Perfusion}

Urinalysis, Renal Function, Plasma Albumin Concentration, and Plasma Electrolytes. Although urinary protein excretion was observed in control rats that were perfused with saline only, rats perfused with elastase showed marked proteinuria (table 1). There were no significant changes in plasma concentrations of urea and creatinine, suggesting that elastase did not have an immediate effect on renal function. Furthermore, plasma albumin concentrations were maintained at baseline levels even in rats perfused with elastase. No effects of renal elastase perfusion on plasma electrolytes were observed. 


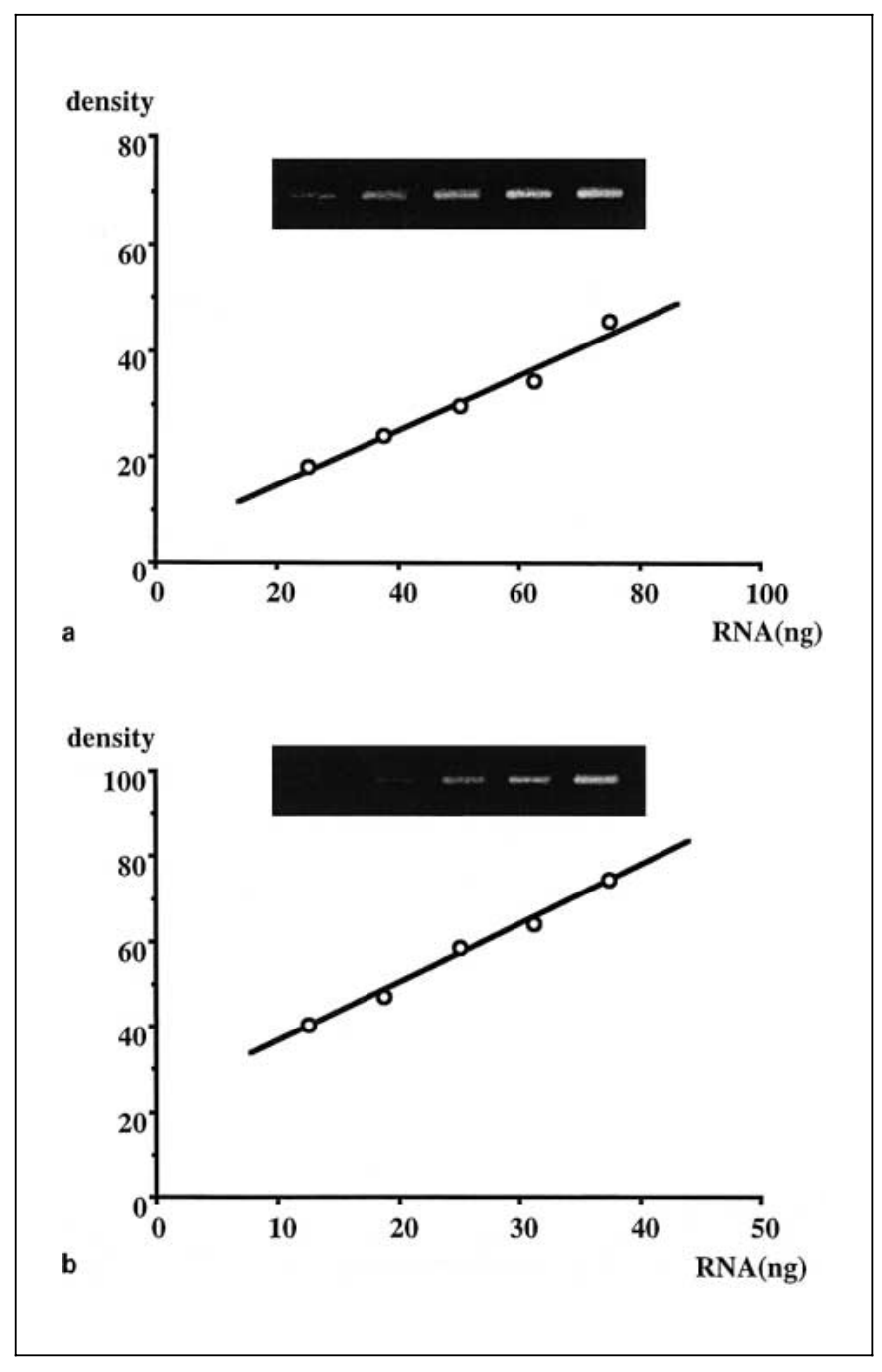

Fig. 2. PCR signals for GAPDH and $\alpha 3$ (IV) with series of different amounts of RNA. a GAPDH signals ( 25 cycles of PCR) showing linear increase from 25 to $75 \mathrm{ng}$ RNA. b Signals for $\alpha 3$ (IV) ( 35 cycles) showing a linear increase from 12.5 to 37.5 ng RNA.

$\alpha 3(I V)$ Transcripts. Figure 3 shows glomeruli from rats with renal elastase perfusion (E-1,2,3, and 4). The signals for $\alpha 3$ (IV) mRNA are lower and irregular in most of GEC (E-1) or some of GEC (E-2,3, and 4). Figure 4a demonstrates the results of PCR signals of each rat for GAPDH and $\alpha 3$ chain of IV collagen. The density of $\alpha 3$ (IV) signal was normalized by that of GAPDH, and the average of five such determinations is depicted in figure $4 \mathrm{~b}$, showing a significant decrease (approximately 25\% decrease) in transcripts signal for $\alpha 3$ (IV) in rats with renal elastase perfusion.
Table 1. Effects of renal perfusion

\begin{tabular}{lcc}
\hline & $\begin{array}{l}\text { Saline } \\
\text { perfusion }\end{array}$ & $\begin{array}{l}\text { Elastase } \\
\text { perfusion }\end{array}$ \\
\hline $\mathrm{n} \quad$ & 8 & 8 \\
Change in the body weight, $\%$ & $8.7 \pm 0.6$ & $8.0 \pm 0.7$ \\
Plasma & & \\
$\quad$ Urea, $\mathrm{mg} / \mathrm{dl}$ & $17.8 \pm 2.0$ & $15.2 \pm 1.9$ \\
$\quad$ Creatinine, $\mathrm{mg} / \mathrm{dl}$ & $0.4 \pm 0.1$ & $0.5 \pm 0.1$ \\
$\quad$ Albumin, g/dl & $1.0 \pm 0.1$ & $1.0 \pm 0.1$ \\
$\quad$ Sodium, $\mathrm{mEq} / \mathrm{l}$ & $140 \pm 1.0$ & $139 \pm 1.0$ \\
$\quad$ Potassium, $\mathrm{mEq} / \mathrm{l}$ & $4.5 \pm 0.1$ & $4.9 \pm 0.3$ \\
Urine & & \\
$\quad$ Volume, $\mathrm{ml} / 24 \mathrm{~h}$ & $17.2 \pm 2.6$ & $16.7 \pm 2.2$ \\
$\quad$ Protein, $\mathrm{mg} / 24 \mathrm{~h}$ & $13.9 \pm 1.1$ & $47.2 \pm 3.8^{*}$ \\
& & \\
\end{tabular}

Values are means \pm SEM. $* \mathrm{p}<0.05$ compared with saline perfusion. Blood sample was obtained $24 \mathrm{~h}$ after renal perfusion.

\section{Discussion}

In the present study, we examined the expression level of transcripts of type IV collagen, which is thought to represent the process of production of basement membrane components in the glomerular epithelium. We selected the cDNA probe for $\alpha 3$ chain of IV collagen, since this unit of type IV collagen is a unique component in GBM in glomeruli [7, 8]. As expected, cDNA probe designating the carboxyl terminal of the $\alpha 3$ (IV) clearly stained the cytoplasmic area of glomerular epithelial cells (GEC), indicating that $\alpha 3(\mathrm{IV})$ is specifically produced in GEC and analysis of its transcripts may show ability of epithelial cells to construct the basement membrane. Renal elastase perfusion, which induced proteinuria without any significant influences on renal function, reduced expression for $\alpha 3$ (IV) mRNA in some of the GEC of rats with renal elastase perfusion. Semiquantitative PCR analysis confirmed the decreased level of expression of the transcripts in the renal cortex of these rats.

Clinical studies examining the effect of oral serine protease inhibitors in patients with nephropathies have demonstrated the antiproteinuric effect of this medication in chronic glomerulonephritis (CGN) [20, 21] and diabetic nephropathy (DN) [20,22]. In addition to CGN where an inflammatory process is thought to be continuously involved in the glomeruli, enhanced leukocyte adhesion to the peripheral capillary of diabetic rats has been noted in association with the onset of diabetic retinopathy [23]. Thus, the clinical findings by protease inhibitor suggest 
Fig. 3. In situ hybridization of $\alpha 3(\mathrm{IV})$ in glomeruli of rats with renal elastase perfusion (E-1,2,3, and 4). Arrows point to glomerular epithelial cells in which signal density for a3(IV) transcripts is lower and irregular. $\times 200$.
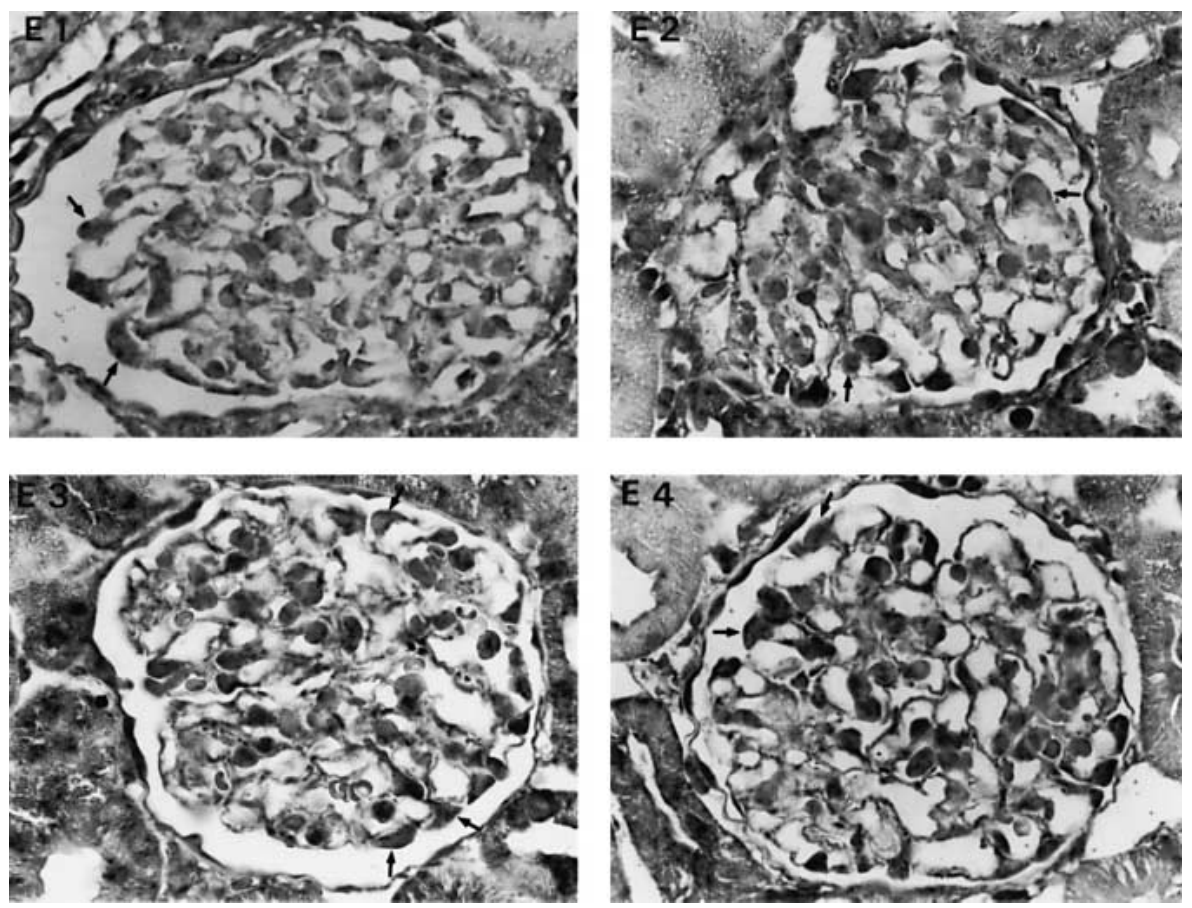

Fig. 4. a PCR signals of each rat for GAPDH and $\alpha 3$ (IV). $\mathbf{b}$ The average of five determinations of signal density for $\alpha 3$ (IV) mRNA, which was normalized to that of GAPDH. $*$ p $<0.05$. 
that proteinuria in $\mathrm{CGN}$ and $\mathrm{DN}$ is induced, in part, by the effects of protease released from activated neutrophils in the glomeruli. Besides, several in vivo studies have demonstrated the direct evidence that circulating elastase induces proteinuria [11-13]. Especially, GBM damage by activated polymorphonuclear leukocytes (PMN) [9, 10], which release protease, or by circulating elastase [13] have been well examined. Therefore, our hypothesis before the study was that the production of GBM components would be promoted in GEC after renal elastase perfusion in order to repair injured basement membrane, and the enhanced production would be manifested by an increase in the transcripts for GBM component. Accordingly, we applied our new techniques of detecting the transcripts for the components of GBM. The results of in situ hybridization, however, clearly demonstrated reduced expression for $\alpha 3$ (IV) mRNA in some of the GEC of rats perfused with elastase, suggesting that production of GBM components may be impaired in these cells. This reduced expression of the $\alpha 3$ (IV) mRNA in the cortex from rats with renal elastase perfusion was further confirmed by semiquantitative PCR.

Besides the ability of protease to degrade extracellular matrix like GBM, several studies have shown that neutral serine protease can also injure endothelial cells (EC) [14, 15]. Although no histological findings of endothelial cell injury was observed in the glomeruli of the rats with renal elastase perfusion in the present study, histological evidence for the degradation of GBM has not been noted [11, 12] until Heeringa et al. [13] examined using immunochemical staining. Thus, the glomerular endothelium, which was directly exposed to circulating elastase, was possibly damaged by circulating elastase. In combination with GBM degradation, EC injury in the glomeruli may also allow the direct exposure of elastase to some of GEC. Focal defects of $\alpha 3$ (IV) mRNA staining observed in rats with renal elastase perfusion may result from degradation of GEC which were exposed to elastase.

Activation of PMN adherent to the glomerular capillary wall leads to the production of reactive oxygen species and the release of their granule constituents, including serine protease. At the site of degranulation high concentration of these proteolytic enzymes may be reached which may cause glomerular injury as observed in PMNdependent GN [9, 10]. Although the effects of these enzymes on the glomerular mesangial cells are still unknown, our present findings indicate that enzymes released from activated PMN may damage GEC in addition to GBM and glomerular EC, influencing on the process of reconstruction of injured GBM.

In conclusion, in situ hybridization using cDNA probe for $\alpha 3$ (IV) mRNA clearly identified cytoplasmic region of the glomerular epithelium. The staining intensity was modified in the pathological condition induced by renal elastase perfusion, suggesting the adverse effects of elastase on glomerular epithelial cells.

\section{Acknowledgments}

This work was supported by Grant-in-Aid for Scientific Research (C, 13671095) from the Ministry of Education, Culture, Sports, Science and Technology. We thank Ms. Kiyomi Kisu and Ms. Mika Mikami for their excellent technical assistance, and Ms. Hiroko Ikeda, Ms. Noriko Takano, and Miss Akiko Kohinata for their secretarial assistance.

\section{References}

1 Mundel P, Kriz W: Structure and function of podocytes: An update. Anat Embryol 1995; 192:385-397.

2 Watanabe H, Sakai T, Kobayashi N, Fukuda Y, Yabuta K: Glomerular basement membrane ourpockets and glomerular growth in the postnatal development of the kidney. Pediatr Nephrol 1996;10:461-466.

3 Nagata M, Watanabe T: Podocytes in metanephric organ culture express characteristic in vivo phenotype. Histochem Cell Biol 1997; 108:17-25.

4 Timpl R, Wiedemann H, Van Delden V, Furthmayr H, Kuhn K: A network model for the organization of type IV collagen molecules in basement membrane. Eur J Biochem 1981; 120:203-211.
5 Hudson BG, Reeders ST, Tryggvason K: Type IV collagen: Structure, gene organization, and role in human disease. Molecular basis of Goodpasture and Alport syndromes and diffuse leiomyomatosis. J Biol Chem 1993;268: 26033-26036.

6 Zhou J, Ding M, Zhao ZH, Reeders ST: Complete primary structure of the sixth chain of human, basement membrane collage, alpha 6(IV): Isolation of the cDNAs for alpha 6(IV) and comparison with five other type IV collagen chains. J Biol Chem 1994;269:1319313199 .
7 Sado Y, Kagawa M, Kishiro Y, Sugihara K, Naito I, Seyer JM, Sugimoto M, Oohashi T, Nijnomiya Y: Establishment by the rat lymph node method of epitope-defined monoclonal antibodies recognizing the six different $\alpha$ chains of human type IV collagen. Histochem Cell Biol 1995;104:267-275.

8 Nonomiya Y, Kagawa M, Iyama K, Naito I, Kishiro Y, Seyer JM, Sugimoto M, Oohashi T, Sado Y: Differential expression of two basement membrane collagen genes, COL4A6 and COL4A5, demonstrated by immunofluorescence staining using peptide-specific monoclonal antibodies. J Cell Biol 1995;130:12191229 . 
9 Baricos WH, Shah SV: Proteolytic enzymes as mediators of glomerular injury. Kidney Int 1991;40:161-173

10 Shah SV, Baricos WH, Basci A: Degradation of human glomerular basement membrane by stimulated neutrophils. J Clin Invest 1987;79: 25-31.

11 Johnson RJ, Couser WG, Alpers CE, Vissers M, Schulze M, Klebanoff SJ: The human neutrophil serine proteinase, elastase and cathep$\sin \mathrm{G}$, can mediate glomerular injury in vivo. $\mathrm{J}$ Exp Med 1988;169:1169-1174.

12 Johnson RJ, Lovett D, Lehrer RI, Couser WG Klebanoff SJ: Role of oxidants and proteases in glomerular injury. Kidney Int 1994;45:352359.

13 Heeringa $\mathrm{P}$, Van Den Born J, Brouwer E, Dolmam KM, Huitema MG, Limburg PC, Bakker MAH, Berden JHM, Daha MR, Kallenber CGM: Elastase, but not proteinase 3 (PR3), induced proteinuria associated with loss of glomerular basement membrane heparan sulphate after in vivo renal perfusion in rats. Clin Exp Immunol 1996;105:321-329.
14 Klebanoff SJ, Kinsella MG, Wight TN: Degradation of endothelial cell matrix heparan sulfate proteoglycan by elastase and the myeloperoxidase- $\mathrm{H}_{2} \mathrm{O}_{2}$-chloride system. Am J Pathol 1993;143:907-917.

15 Ballieux BEPB, Hiemstra PS, Klar-Mohamad $\mathrm{N}$, Hagen EC, van Es LA, van der Woude FJ, Daha MR: Detachment and cytolysis of endothelial cells by proteinase 3 . Eur J Immunol 1994;24:3211-3215.

16 Michimata M, Nogae S, Ohta M, Kaizuma S, Imai Y, Ito S, Matsubara M: Topographic distribution of aquaporin 2 mRNA in the kidney of dehydrated rats. Exp Nephrol 2000;8:2836.

17 Nogae S, Michimata M, Kanazawa M, Honda S, Ohta M, Imai Y, Ito S, Matsubara M: Cardiac infarcts increase sodium transporter transcripts (rBSC1) in the thick ascending lim of Henle. Kidney Int 2000;57:2055-2063.

18 Marumo M, Kaizuma S, Nogae S, Kanazawa M, Kimura T, Saito T, Ito S, Matsubara M: Differential upregulation of rat $\mathrm{Na}-\mathrm{K} \mathrm{Cl}$ cotransporter, rBSC1, mRNA in the thick ascending limb. Kidney Int 1998;54:877-888.
19 Michimata M, Wang W, Fujita S, Haruo M, Fujimori K, Satomi S, Ohta M, Ito S, Kimura T, Araki T, Imai Y, Matsubara M: Limited urinary concentration and damaged tubules in rats with a syngeneic kidney graft. Kidney Int 2002;60:672-679.

20 Matsubara M, Taguma Y, Kurosawa K, Hotta O, Suzuki K, Futaki G: Effect of camostat mesilate on heavy proteinuria in various nephropathies. Clin Nephrol 1989;32:119-123.

21 Matsubara M, Taguma Y, Saito T, Yoshinaga $\mathrm{K}$ : Effect of camostat mesilate on persistent proteinuria of IgA nephropathy. Nephron 1992;60:244-245.

22 Matsubara M, Taguma Y, Kurosawa K, Hotta O, Suzuki K, Ishizaki M: Effect of camostat mesilate for the treatment of advanced diabetic nephropathy. J Lab Clin Med 1990;116:20210.

23 Kinukawa Y, Shimura M, Tamai M: Quantifying leukocyte dynamics and plugging in retinal microcirculation of streptozotosin-induced diabetic rats. Curr Eye Res 1999;18:49-55. 